display in examining the thorax. In conclusion, this book is a 'must' for MRCP candidates and for the general physician seeking a brief update on respiratory medicine.

Martin Hetzel

University College Hospital, London W.C.1

The Staphylococci, Proceedings of the Alexander Ogston Centennial Conference

Edited by Alexander Macdonald and George Smith. Pp. ix +288 , illustrated. Aberdeen University Press, Aberdeen, 1981. $£ 20.00$.

It is 100 years since Alexander Ogston described the Staphylococcus: a centenary celebrated at Aberdeen University, with a symposium. Attempts to produce books from conference proceedings often produce a somewhat disjointed collection of limited aspects of a subject, with a marked variation in standard between papers. This book is notable for not falling into such a category. The authors of the twenty chapters have been carefully selected, and give a concise account of their particular interest.

The book may be divided into a number of linked sections. The first 2 chapters outline the historical interrelationships between Ogston, the developing science of bacteriology, and his early work on the Staphylococcus. Then follows an interesting interlude on Ogston's experiences in the Royal Army Medical Corps.

From the historical aspects, we move to the difficulties of the taxonomy of the staphylococci, admirably described and discussed by Dr Hill. This chapter is followed by a series of papers encompassing host parasite relationships, immunology and pathogenicity. From these papers, and a clinical chapter demonstrating the versatility of the staphylococcus, the reader comes to appreciate how much still remains unknown about this ubiquitous organism, in spite of the amount of fruitful research that has been done.

The epidemiology of staphylococcal infections, particularly with regard to the classical hospital epidemics, and the carrier state is covered in a series of chapters by among others, Prof. Shooter, Dr Parker, and Dr Lidwell-all experts in this field. A chapter on infection in the tropics underlines the versatility and mystery of this organism. Prof. Lambert describes the antimicrobial sensitivity of the staphylococcus, concentrating on the treatment of severe infections. Finally, a masterly summary of the history and bacteriology of the organism is given by Sir R. E. O. Williams

The appendix is a translation of Ogston's original presentation, and if read first, sets the scene for the rest of the book. More than a centennial tribute, this book is useful as a reference source. What a pity it was not possible to provide an index to allow easier access to the wealth of information.

One further minor criticism is the cost-twenty pounds for 288 pages must restrict the market to department libraries, where it will be a worthwhile addition.

G. L. RIDGWAY

University College Hospital, London W.C.1

\section{Suppressor Cells in Human Disease}

Edited by JAMES S. Goodwin. Immunology Series vol. 14. Pp. $x+363$, illustrated. Marcel Dekker, New York, 1981. Sw.Fr 118.00.

Immunology is such a rapidly growing subject that it is difficult for even the specialist to keep up to date. There is therefore a need for review style articles and books dealing with particular areas and this book is designed to fulfil such a need. Problems arise, however, when there is a time-lag between writing the chapters (especially true for a multiauthor book) and publication, for the concepts may well be out of date. This book would have been a good one two years ago but so much new information has accumulated in this time that, as published now, the book is sadly deficient. The first few chapters cover the basic areas with regard to suppression, i.e. macrophage interaction, prostaglandin and cyclic AMP regulation and HLA-D locus restriction. The remaining chapters deal with suppressor cells-lack or overactivity in diseases such as autoimmunity, immunodeficiency and cancer.

The book was written at the time that monoclonal antisera recognizing $T$ cell subsets in man had just been described. There is now a wealth of literature on these $T$ cell subpopulations in different diseases. Absent too are the new experiments on helper and suppressor factors, on $\mathrm{T}$ cell lines producing suppressor factors and whether major histocompatibility antigens restrict the function of these 'lymphokines'.

I sympathize with the authors-it was courageous to attempt to put together such a book. It is still valuable reading for the general physician and immunologist not working in the field since good and up-to-date reviews are not published frequently.

Roland LEVINSKY Institute of Child Health, 30 Guilford Street, London, W.C.1. 